\title{
T-stress determination using thermoelastic stress analysis
}

M Zanganeh, R A Tomlinson*, and J R Yates

Department of Mechanical Engineering, University of Sheffield, UK

The manuscript was received on 7 September 2007 and was accepted after revision for publication on 14 May 2008.

DOI: $10.1243 / 03093247 J S A 349$

\begin{abstract}
T-stress and mixed-mode stress intensity factors have been determined experimentally using thermoelastic stress analysis and using a finite element method. Pure mode I, strong mixed-mode I and II, and interacting cracks have been used as the case studies. A new technique has been proposed to identify the crack tip from thermoelastic images. It has also been shown that using three terms of Williams's stress field formulation to determine the Tstress, yields a more accurate solution than using only the first two terms of the expansion.
\end{abstract}

Keywords: T-stress, stress intensity factor, thermoelastic stress analysis

\section{INTRODUCTION}

It has been observed that there are many circumstances in which an elastic, or elastic-plastic, parameter is not able to characterize fully the strain field ahead of a loaded crack. Larsson and Carlson [1] applied the same level of stress intensity factor (SIF) to specimens with different geometries. They observed that different plastic zone sizes and different crack opening displacements were obtained. Recently studies have attempted to use a second parameter in elastic fracture mechanics to describe the crack tip stress state more accurately. A useful second parameter is the T-stress which is defined as the second non-singular term in Williams's [2] crack tip stress field solution. Stresses, for mode I, are

$\sigma_{x x}=\frac{K_{\mathrm{I}}}{\sqrt{2 \pi r}} \cos \frac{\theta}{2}\left(1-\sin \frac{\theta}{2} \sin \frac{3 \theta}{2}\right)+T+A \sqrt{r} \cos \frac{\theta}{2}\left(1+\sin ^{2} \frac{\theta}{2}\right)+O(r)$ $\sigma_{y y}=\frac{K_{\mathrm{I}}}{\sqrt{2 \pi r}} \cos \frac{\theta}{2}\left(1+\sin \frac{\theta}{2} \sin \frac{3 \theta}{2}\right)+A \sqrt{r} \cos \frac{\theta}{2}\left(1-\sin ^{2} \frac{\theta}{2}\right)+O\left(r^{3 / 2}\right)$ $\tau_{x y}=\frac{K_{\mathrm{I}}}{\sqrt{2 \pi r}} \cos \frac{\theta}{2} \sin \frac{\theta}{2} \cos \frac{3 \theta}{2}-A \sqrt{r} \sin \frac{\theta}{2} \cos ^{2} \frac{\theta}{2}+O(r)$

and for mode II are

* Corresponding author: Department of Mechanical Engineering, University of Sheffield, Mappin Street, Sheffield, S1 3JD, UK. email: r.a.tomlinson@sheffield.ac.uk

$$
\begin{aligned}
\sigma_{x x} & =\frac{-K_{\mathrm{II}}}{\sqrt{2 \pi r}} \sin \frac{\theta}{2}\left(2+\cos \frac{\theta}{2} \cos \frac{3 \theta}{2}\right)+B \sqrt{r} \sin \frac{\theta}{2}\left(2+\cos ^{2} \frac{\theta}{2}\right)+O(r) \\
\sigma_{y y} & =\frac{K_{\mathrm{II}}}{\sqrt{2 \pi r}} \sin \frac{\theta}{2} \cos \frac{\theta}{2} \cos \frac{3 \theta}{2}-B \sqrt{r} \sin \frac{\theta}{2} \cos ^{2} \frac{\theta}{2}+O\left(r^{3 / 2}\right) \\
\tau_{x y} & =\frac{K_{\mathrm{II}}}{\sqrt{2 \pi r}} \cos \frac{\theta}{2}\left(1-\sin \frac{\theta}{2} \sin \frac{3 \theta}{2}\right)+B \sqrt{r} \cos \frac{\theta}{2}\left(1+\sin \frac{\theta}{2} \sin \frac{3 \theta}{2}\right)+O\left(r^{3 / 2}\right)
\end{aligned}
$$

in which $\sigma_{x x}, \sigma_{y y}$, and $\tau_{x y}$ are the stresses at the point of interest at a distance, $r$, and angle, $\theta$, from the crack tip as shown in Fig. $1 . K_{\mathrm{I}}$ and $K_{\mathrm{II}}$ are the mode I and mode II SIFs respectively. $T$ is the T-stress, $A$ and $B$ are constants, and $O$ is the order symbol.

The T-stress is a constant stress parallel to the crack and is a measure of the constraint around the tip of a crack in contained yielding problems [3]. Specimens having a positive T-stress have a higher constraint than those with a negative T-stress. The $\mathrm{T}$-stress is proportional to the remote applied stress [4] and the constant of proportionality changes for different loading and boundary conditions. For example, for a centre-crack in an infinite plate under uniaxial tension, the T-stress at the crack tip equals $-\sigma_{\text {app }}$ where $\sigma_{\text {app }}$ is the remote applied stress [4].

The effect of the T-stress has been extensively investigated (for example, references [1, 3-5]) and it has become evident that the T-stress has a vital role in interpreting many phenomena observed in fracture mechanics. In a perfect isotropic elastic solid a crack will grow perpendicular to the direction of the 


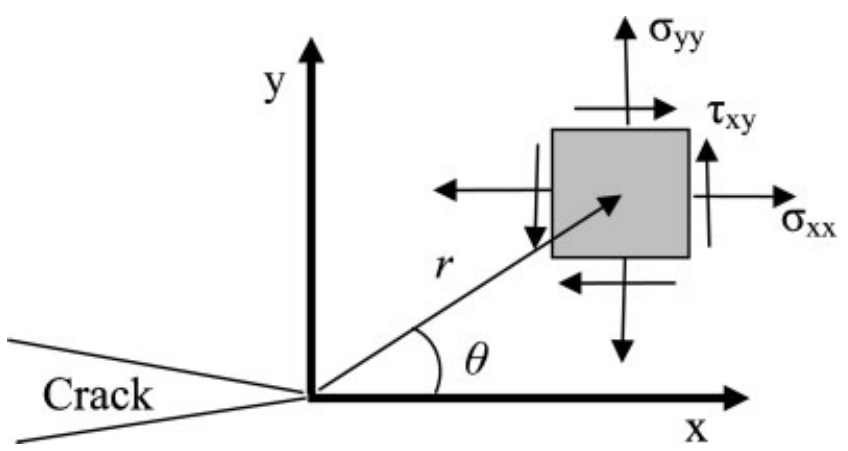

Fig. 1 Stress state ahead of a crack tip

maximum tangential stress [6], i.e. for a mode I crack, $\theta=0^{\circ}$ and the crack will grow in the direction of $r$ in Fig. 1. However, in real engineering materials there may be deviation from the perfect path caused by irregularities in the microstructure [7]. To consider these irregularities and on the basis of the local symmetry criterion, Cotterell [7] used the expanded form of the stress distribution at the crack tip as a power series, in which the first term is proportional to the SIF, and concluded that the T-stress controls the stability of the crack direction. Cotterell assumed that the ideal direction for crack growth is along the line of symmetry of the stress distribution ahead of the crack tip and concluded that if the sign of the Tstress is negative then the crack path has a tendency to return to its original ideal path (referred to as 'directionally stable'). However, if the T-stress is positive the crack path does not return to this original ideal path.

The magnitude of the T-stress can also affect the initiation angle of fracture and consequently the apparent fracture toughness. It was observed by Ayatollahi et al. [5] that when the T-stress exceeds a critical value the maximum tangential stress is no longer along the line of the initial crack and this causes a deviation in initiation angle of fracture. Larger values of $\mathrm{T}$-stress increase this deviation which in turn causes a reduction in apparent fracture toughness. Apart from crack paths, directional stability problems and crack initiation angle, the effects of the T-stress on the crack growth rate, crack tip constraints, crack closure, and the shape and size of the plastic zone ahead of the crack tip have also been assessed by many workers $[\mathbf{8}, \mathbf{9}]$.

Many different methods have been proposed to evaluate the T-stress in different types of specimens. These include the stress substitution, variational formulation, Eshelby J integral, interaction integral, line spring and weight function methods [10]. However, all these approaches are numerical or analytical; their accuracy depends on geometry or mesh refinement and they are only applicable to specific configurations. Therefore, the need to have a robust experimental technique to determine the Tstress and validate simulations is evident.

In recent years, thermoelastic stress analysis (TSA) has proved to be an ideal technique for the determination of mode I, mode II, and mixed SIFs [11-15]. Therefore the aim of this work was to develop these methodologies to determine the Tstress in addition to the SIF.

\section{ELASTIC PARAMETERS DETERMINATION USING TSA}

SIFs determined using TSA are directly obtained from the crack tip stress field rather than being inferred from measurements of the crack length and maximum and minimum loads as in other experimental methods [12]. These characteristics of TSA make it an effective method to be used in fatigue and fracture problems. A number of methodologies for calculating the SIF are available and were reviewed by Tomlinson and Olden [12], with further developments since the publication of the review $[\mathbf{1 1}, \mathbf{1 3}$, 14]. However, little research has been published on the use of other parameters to formulate the crack tip stress state using TSA. Only Dulieu-Barton et al. [14] used two terms in Williams's formulation to determine the SIFs, based on the assumption that the thermoelastic signals around the crack tip are series of cardioids centred at the crack tip. The focus of the work was on SIF calculation rather than Tstress calculation. However, they determined the non-singular term for a plate with a central crack with $0^{\circ}, 30^{\circ}$, and $45^{\circ}$ inclination angle as part of their SIF methodology. Since their derived non-singular terms were small they concluded that this term did not affect the SIF values significantly and thus assumed that the non-singular term was negligible for the rest of their calculations. However, there was a miscalculation in the T-stress determined, since for the centre-cracked plate the T-stress should have equalled the remote applied stress [4] but the value was an order of magnitude too low. This miscalculation made their conclusion invalid and their technique not suitable, at least for determining the nonsingular term or T-stress. However, their SIF methodology is robust.

One of the most important issues in experimentally determining crack tip parameters is choosing an appropriate mathematical description of the stress field to which the experimental data are fitted in order to solve for these parameters. Two different 
mathematical descriptions have been used to determine the SIFs from TSA data: Williams's equations and the Muskhelishvili solutions [15]. However, since the Muskhelishvili approach makes it only possible to determine the SIFs, the only applicable model to determine the T-stress and SIF is Williams's formulation. Since equations (1) are an expanded series of many terms, the parameter to be explored is the number of terms that should be used to obtain reasonable results. However, previous studies [13] have highlighted the importance of accurate location of the crack tip and so this was also included in these studies.

\section{CRACK TIP POSITION}

It has been shown in previous work in determining the SIF from TSA data that locating the crack tip within the field of data has a significant influence on the calculated parameters [13]. This is because the coordinate systems for full field data collection and processing are generally relative to the crack tip (see equations (1) [2]. It is of interest to note, however, that an early publication [16] on this topic presented a method for SIF determination that does not require an accurate knowledge of the crack tip position, and also in a later publication by one of the same authors [14]. Several different methods have been proposed so far to find the crack tip position from thermoelastic images $[13,14,17]$. The TSA image can be presented as a vector with magnitude ( $\mathrm{R}$ image) and phase (which is the phase shift between the TSA signal and the reference signal); or as the projection of the vector in $X$ (X image) and $Y(\mathrm{Y}$ image) directions in the Cartesian coordinate system, where the $\mathrm{X}$ image is the inphase image and the Y image is the out-of-phase image. Most of the proposed methods use the magnitude of the thermoelastic signal (the $\mathrm{X}$ or $\mathrm{R}$ image) to estimate the position of the crack tip. Recently Diaz et al [13] attempted to overcome the problem of locating the crack tip by including the crack tip coordinates as two additional variables in the optimization process to calculate the Fourier series coefficients in the Muskhelishvili approach using a downhill simplex (DS) method. As an alternative, a genetic algorithm (GA) was also used to find an initial value for the DS method to solve the same problem. However, both of these methods are based on numerical techniques rather than any physical basis and are very slow. Therefore an alternative is proposed in this paper to locate the position of the fatigue crack tip from thermoelastic images using the phase signal.

The concept of using the thermoelastic phase image to find the approximate location of the crack tip was first proposed by Diaz et al. [13]. Figure 2 shows the phase signal along a line taken through a crack tip and co-linear with the crack, and is typical for all fracture problems. They divided the phase image into three different regions. Region A is the region where the adiabatic condition prevails and the thermoelastic signal and the load signal are in phase. Region B was defined as a region where there is a higher gradient of stress and the out-of-phase signal indicates that the adiabatic condition is lost. They assigned region $\mathrm{C}$ as an indication of heat

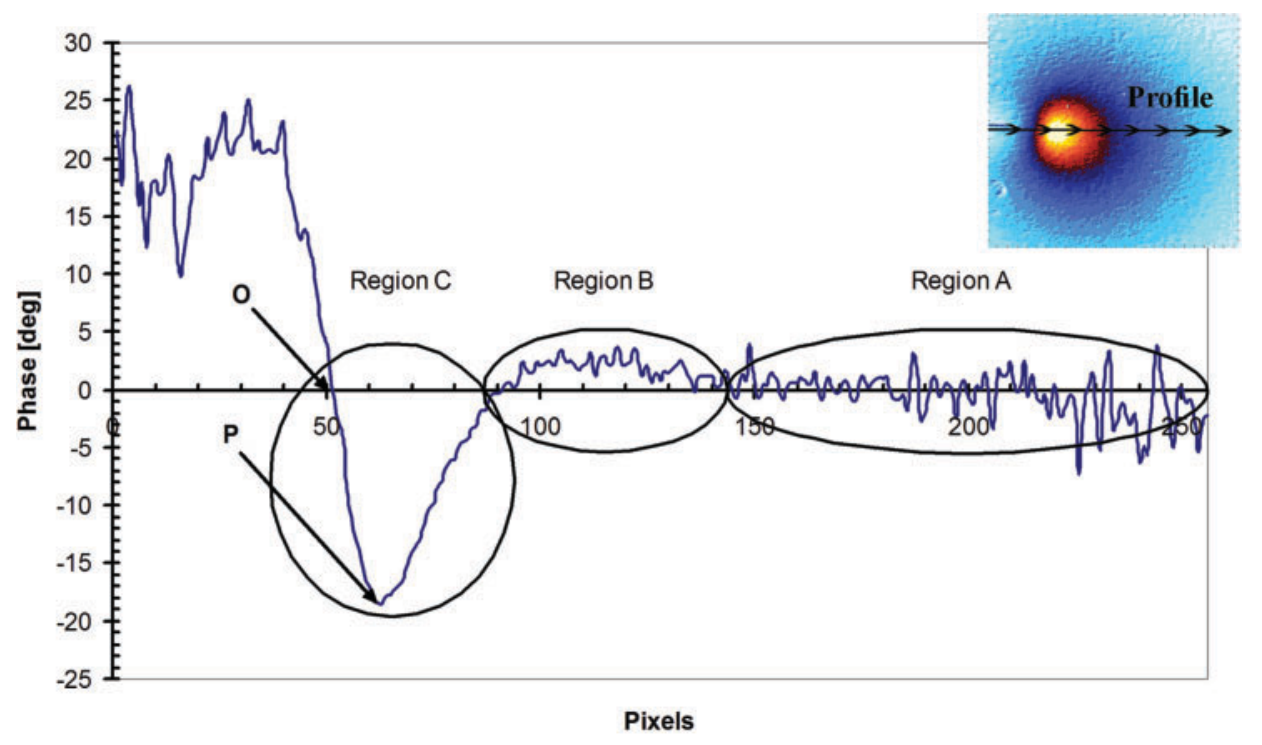

Fig. 2 A typical phase shift diagram ahead of the crack tip 

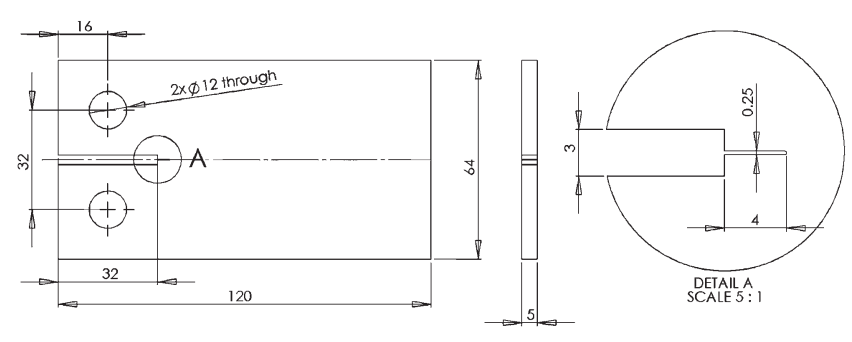

(a)

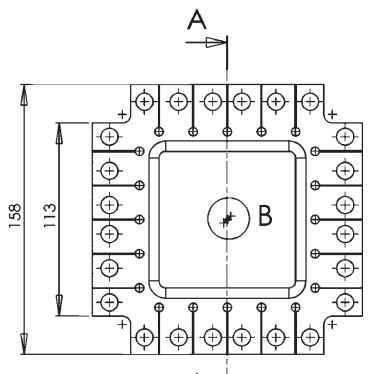

A

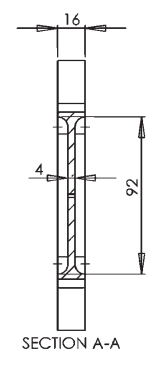

(b)

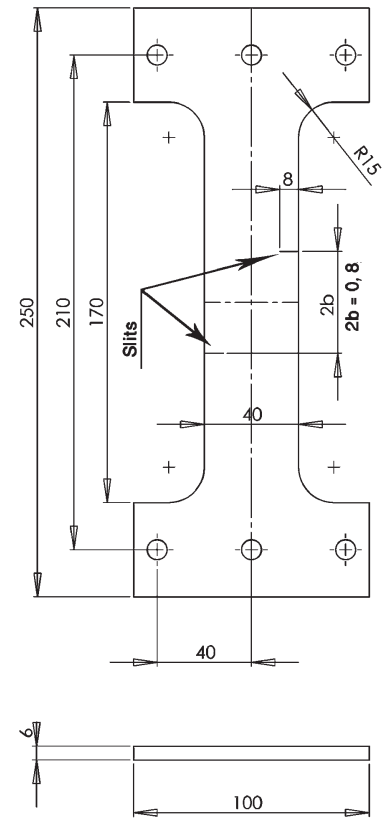

(c)

Fig. 3 Specimen dimensions: (a) DCB; (b) cruciform; (c) DEC

generation due to plasticity ahead of the crack tip. Therefore, point $\mathrm{O}$ was adopted as an estimation for the crack tip and used as an initial value for their GA/ DS method to solve for the SIFs and the optimized crack tip position.

It is reasonable that the phase shift around the crack tip is due to a high stress gradient and plasticity ahead of the crack tip. However, since the size of the plastic zone ahead of the crack tip, especially in the early stages of crack growth, is of the order of the resolution of the camera and the highest stress gradient still exists in the crack tip, it is postulated that the phase image should have an extreme value at the crack tip rather than zero. Therefore, it is more likely that the actual crack tip is at point $\mathrm{P}$ and therefore experiments were performed to investigate this hypothesis. It should be noted that the location of point $\mathrm{P}$ can be determined equally well using either the thermoelastic $\mathrm{Y}$ image or the phase image since both show the same out of phase characteristics.

\section{EXPERIMENTS}

\subsection{Crack tip location}

In order to investigate the applicability of using point $\mathrm{P}$ as the crack tip position in the TSA images, a double cantilever beam (DCB) specimen (Fig. 3(a)) was manufactured from 7010 T7651 aluminium alloy. A $0.25 \mathrm{~mm}$ notch of length $4 \mathrm{~mm}$ was spark eroded in the specimen (Fig. 3(a)). Then the surface of the specimen was prepared for TSA by spraying with matt black paint (type no. 496-782 RS Components Ltd, UK) and a cyclic load, $0.5 \mathrm{kN}$ to $1.5 \mathrm{kN}$, was applied at $25 \mathrm{~Hz}$ until the crack grew to $0.65 \mathrm{~mm}$. A TSA image was recorded using a 1410 Deltatherm system and the crack length was measured using a travelling microscope. The fatigue crack was grown further to lengths of 1.39 and $2.42 \mathrm{~mm}$ and the procedure was repeated. The TSA images were analysed and the crack tip was found using the $\mathrm{Y}$ image or phase-image ( $\mathrm{Y} /$ phase) technique, i.e. locating point $\mathrm{P}$ as in Fig. 2. These results were compared with the crack tip location found by the GA/DS method described by Diaz et al. [13] and with the measurements from the travelling microscope in Table 1.

Further TSA data were recorded from notch tips from five different specimens since locating a notch tip from a TSA image by visual inspection is

Table 1 Comparison between the Y/phase-image and the GA/DS techniques to measure the fatigue crack length (in $\mathrm{mm}$ )

\begin{tabular}{lll}
\hline $\begin{array}{l}\text { Crack length } \\
\text { measured using } \\
\text { microscope }\end{array}$ & $\begin{array}{l}\text { Y/phase-image crack } \\
\text { length }\end{array}$ & GA/DS crack length \\
\hline 0.65 & 0.703 & 0.082 \\
1.39 & 1.47 & 0.562 \\
2.42 & 2.391 & 2.069 \\
\hline
\end{tabular}


straightforward (compared with a fatigue crack tip). The specimens used were a DCB specimen and four cruciform specimens with different notch lengths (see Fig. 3(b) and Table 2 for geometry). The coordinates of the notch tips in each of the TSA images were found using the Y/phase-image technique and again the GA/DS method, and were compared with the notch location found by visual inspection. The results are shown in Table 2.

\subsection{T-stress and SIF determination}

The T-stress and SIFs were determined for six different conditions which included: pure mode I, mixed mode I and II, and interacting crack tip fields. The dimensions of the specimens are shown in Fig. 3 and Table 3 details the specimens, crack lengths, and loading conditions. A $100 \mathrm{kN}$ Mand hydraulic test machine was used to load the specimens in all cases except cases 3 and 4 where a $100 \mathrm{kN}$ Denison Mayes biaxial testing machine was used to apply the load.

Figure 4 shows the qualitative results gained from TSA of the different cases given in Table 3 . As is well known, under adiabatic and reversible conditions the thermoelastic signal, $S$, is proportional to the variation of the sum of the principal stresses. Assuming plane stress conditions and using equations (1), the sum of the principal stresses can be written based on Williams's solution as a series expansion [2]

$$
\begin{aligned}
\Delta\left(\sigma_{x x}+\sigma_{y y}\right)= & \Delta\left(\sigma_{11}+\sigma_{22}\right)=\frac{2}{\sqrt{2 \pi r}} \Delta K_{\mathrm{I}} \cos \frac{\theta}{2} \\
& -\frac{2}{\sqrt{2 \pi r}} \Delta K_{\mathrm{II}} \sin \frac{\theta}{2}+\Delta T+2 A \sqrt{r} \cos \frac{\theta}{2} \\
& +2 B \sqrt{r} \sin \frac{\theta}{2}+O(r)
\end{aligned}
$$

where $\sigma_{11}$ and $\sigma_{22}$ are the principal stresses at the point of interest with distance, $r$, and angle, $\theta$, from the crack tip. The crack tip positions were found using the Y/phase-image (point P) as well as the GA/ DS technique.

A code was developed to collect experimental data points in the thermoelastic image from the region dominated by the crack tip stress field. Approximately 300 data points were taken from the linear elastic region surrounding the crack tip, where the effect of the through thickness stress is negligible, using a data collection method described by Diaz et al. [13]. A least squares method was used to solve the over-determined system of equations for $\Delta K_{\mathrm{I}}$, $\Delta K_{\mathrm{II}}$, and $\Delta \mathrm{T}$-stress for up to the order of $O(r)$ using equation (2).

In parallel with the experiments, the finite element (FE) method, ABAQUS/CAE [18], was used to find the SIFs and T-stress. In order to check the accuracy of the numerical analysis, a uniaxial tensile model was generated for a centre-crack in a large plate with

Table 2 Comparison between $x$ and $y$ tip coordinates from the Y/phase-image and the GA/DS techniques to find the location of the notch tip (in pixels)

\begin{tabular}{|c|c|c|c|c|c|c|c|}
\hline \multirow[b]{2}{*}{ Case no. } & \multirow[b]{2}{*}{ Type } & \multirow[b]{2}{*}{ Material } & \multirow{2}{*}{$\begin{array}{l}\text { Notch length } \\
(\mathrm{mm})\end{array}$} & \multirow{2}{*}{$\begin{array}{l}\text { Fatigue crack } \\
\text { length }(\mathrm{mm})\end{array}$} & \multirow{2}{*}{$\begin{array}{l}\text { Frequency } \\
(\mathrm{Hz})\end{array}$} & \multicolumn{2}{|c|}{ Loading (kN) } \\
\hline & & & & & & $\Delta F_{x}$ & $\Delta F_{y}$ \\
\hline 1 & DCB & $\mathrm{Al} 7010$ & 4 & 0 & 25 & 0 & 0.5 to 1.5 \\
\hline 2 & DCB & Al 7010 & 4 & 2.42 & 25 & 0 & 0.5 to 1.5 \\
\hline 3 & Cruciform & 150M36 steel & 9 & 0 & 8 & 0.3 to 10.3 & 0.1 to 10.1 \\
\hline 4 & Cruciform & 150M36 steel & 9 & 0 & 8 & 0.1 to 5.0 & 0.1 to 14.7 \\
\hline 5 & $\begin{array}{l}\text { DEC } 0 \text { offset, left } \\
\text { crack }\end{array}$ & $\mathrm{Al} 7010$ & 8 & 0 & 20 & 0 & 1 to 7 \\
\hline 6 & $\begin{array}{l}\text { DEC } 0 \text { offset, right } \\
\text { crack }\end{array}$ & Al 7010 & 8 & 0 & 20 & 0 & 1 to 7 \\
\hline
\end{tabular}

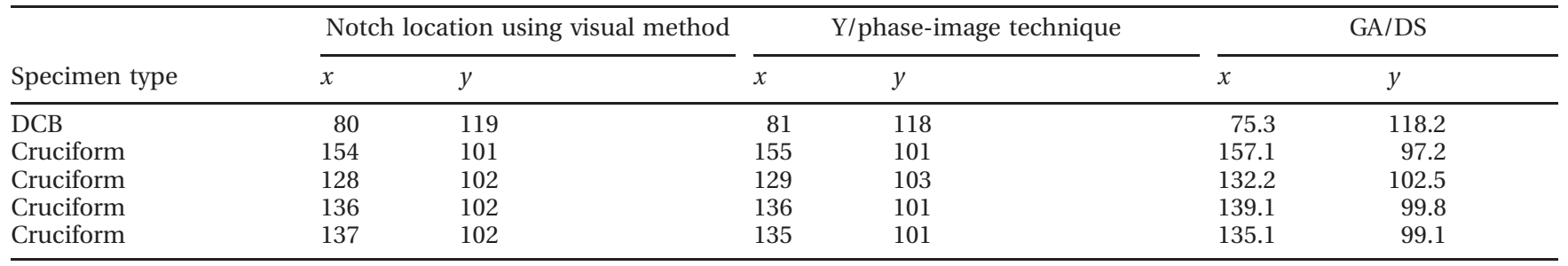

Table 3 Experimental details for the specimens used in the T-stress and SIF determination

$F$ is the load applied to the specimen. 


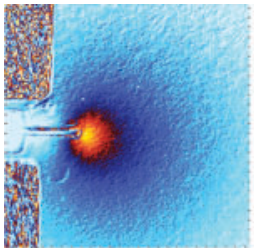

Case 1

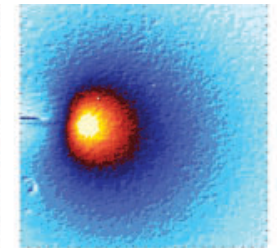

Case 2

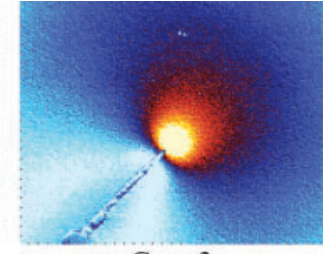

Case 3

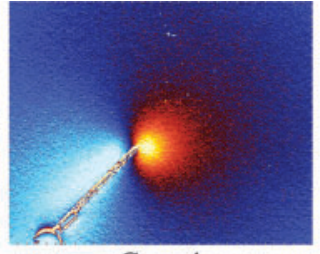

Case 4

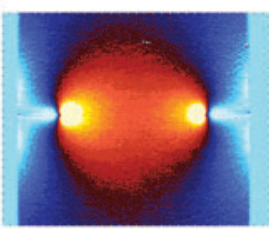

Cases 5 and 6

Fig. 4 Thermoelastic images for the different cases used to validate the T-stress determination method

$a / w=0.08$ and $w / h=1$, in which $a$ is the crack length, $w$ is the width of the specimen, and $h$ is the height of the specimen. The T-stress was determined for a range of loads and compared with an analysis published by Fett [19]. The results showed only 0.6 per cent difference when compared with the published data. A double-edge-cracked (DEC) rectangular plate $(a / w=0.4$ and $h / w>1.5)$ was also modelled using the FE method. In this case T-stress results were about 2 per cent different from those in reference [19].

A comparison between the numerical simulation and experimental results is shown in Fig. 5. This shows the effect of using equation (2) up to the order of $O\left(r^{1 / 2}\right)$, i.e. two terms of Williams's solution, and up to the order of $O(r)$, i.e. three terms of Williams's solution, on $\Delta K_{\mathrm{I}}, \Delta K_{\mathrm{II}}$, and $\Delta \mathrm{T}$-stress. The effect of crack tip location found by means of the Y/phaseimage technique and GA/DS technique on the determined SIFs and T-stress is shown in Fig. 6. A comparison is made between those results and the FE results.

\section{DISCUSSION}

The main area of investigation during this research was to establish how many terms of the Williams' equations (2) were needed to determine the T-stress accurately using TSA data. This was done by comparing the experimentally determined T-stress for a range of six different test conditions with corresponding values determined from finite element analysis (FEA). The FEA was used as a datum since the FEA methodology was found to give results for T-stress comparable with previously published data for standard specimens [19]. It can be seen in Fig. 5(a) that the FEA compares well with the experimentally determined T-stress using three terms of Williams's equations but using only two terms introduces considerable differences, in terms of magnitude and sign. As discussed in the Introduction, in addition to the magnitude [5], the sign of $\mathrm{T}$-stress is also crucial in crack directional stability problems $[\mathbf{7 , 2 0}]$. It is therefore important that the experimental technique should be able to determine the sign and magnitude of the T-stress properly. One of the reasons that the non-singular term found by Dulieu-Barton et al. [14] did not agree with the analytical solution may be that their method is based on using only two terms of Williams's solution,

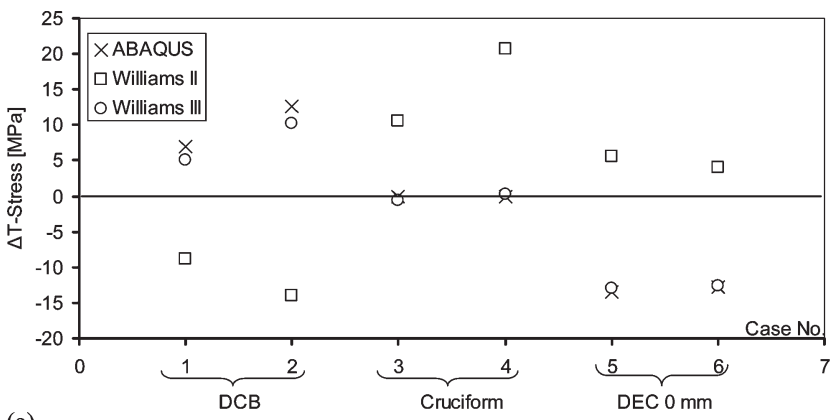

(a)

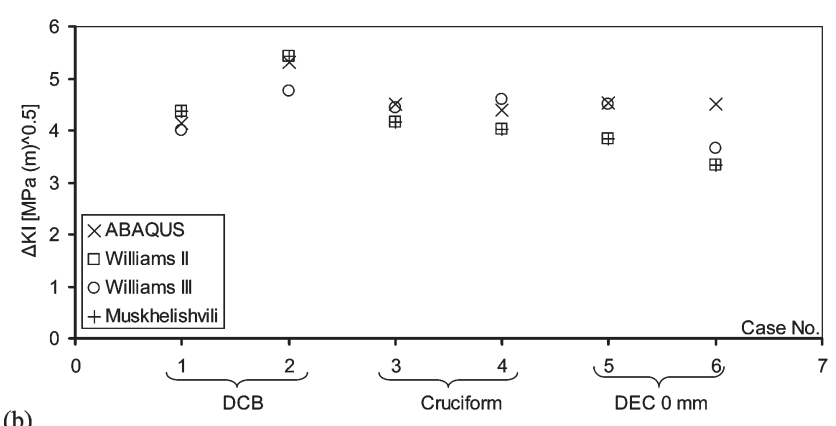

(b)

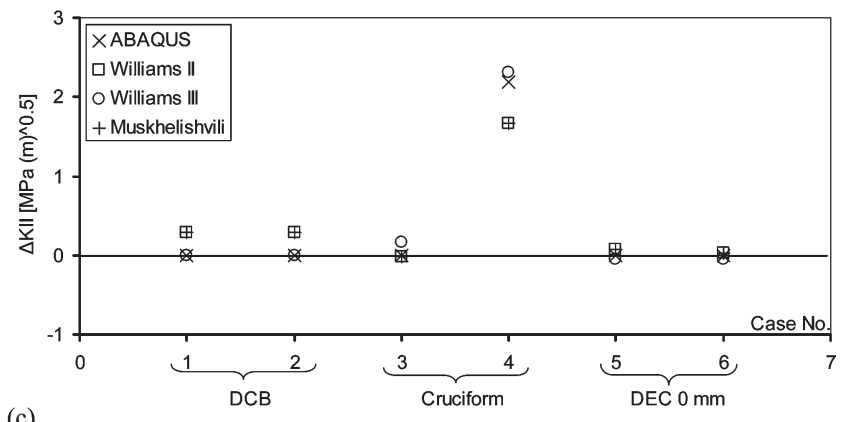

Fig. 5 Comparison of ABAQUS, two- and three-terms Williams's solution, and Muskhelishvili's solution for: (a) $\Delta \mathrm{T}$-stress; (b) $\Delta K_{\mathrm{I}}$; (c) $\Delta K_{\mathrm{II}}$. See Fig. 4 for the thermoelastic images 


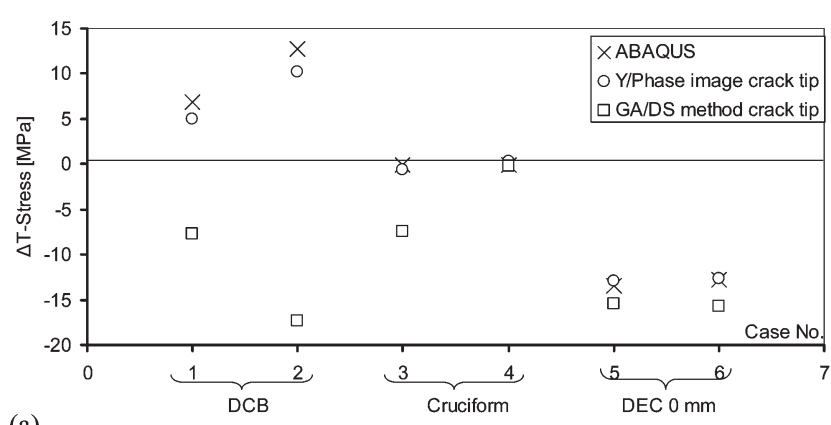

(a)
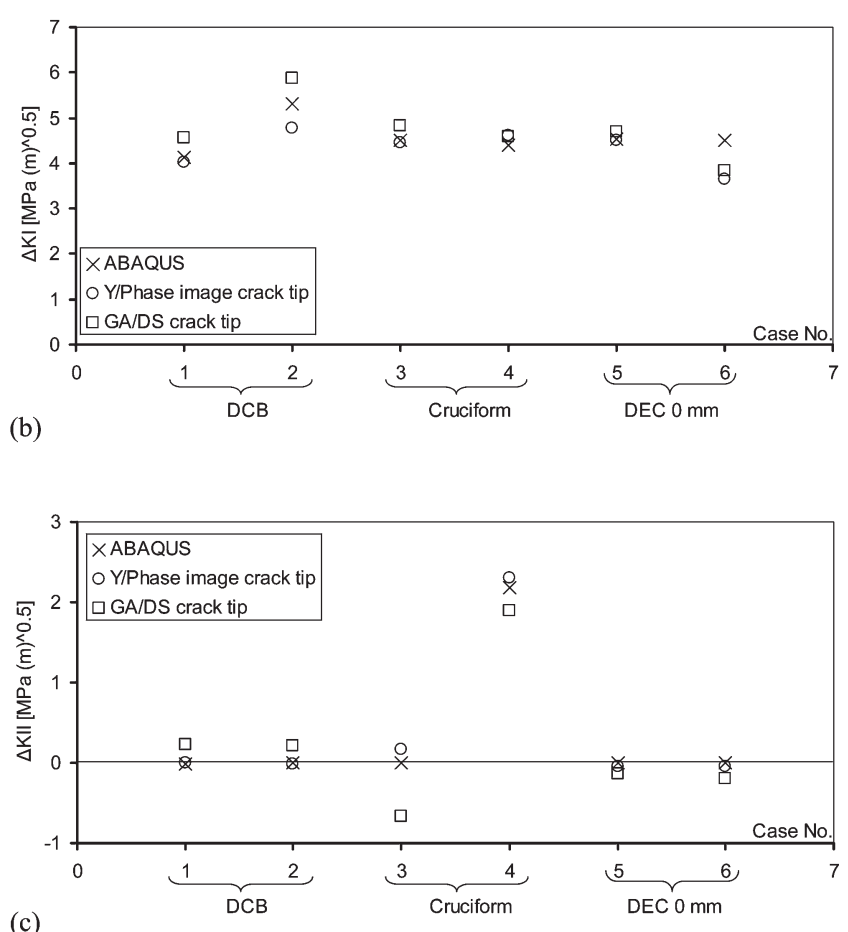

Fig. 6 Comparison based on crack tip found by GA/ DS and Y/phase-image techniques using the three-terms Williams's solution: (a) $\Delta \mathrm{T}$-stress; (b) $\Delta K_{\mathrm{I}}$; (c) $\Delta K_{\mathrm{II}}$. See Fig. 4 for the thermoelastic images

which is shown in Fig. 5(a) to be insufficient. However, using the third term as well to determine the T-stress significantly improves the results when compared with the numerical solution in all of the cases considered.

In addition to using Williams' solution to determine the SIFs, the Muskhelishvili solution [13] was also used and it was found that the results determined using this formulation coincide exactly with the results using two terms of the Williams's solution as shown in Figs 5(b) and 5(c). It can be observed from Fig. 5(b) that the mode I SIF determination using up to three terms of Williams's solution shows comparable results with those obtained using two terms in all cases. It was considered, however, that for the mode II SIF determination (Fig. 5(c)) using three terms in Williams's equations gives a marginally better comparison with the FEA results than using only two terms.

Thus, using the Muskhelishvili solution or two terms of Williams's solution does not introduce a significant error when compared with a three-terms solution in SIF determination, but the use of these terms affects the T-stress results noticeably in terms of magnitude and sign. Therefore it is recommended that three terms of Williams's solution should be used for T-stress determination from thermoelastic data.

It can be seen in Tables 1 and 2 that the Y/phaseimage technique is more reliable than the other technique in finding the crack tip from thermoelastic images when compared with a manual/visual method. It is considered that the GA/DS method may be improved by using a more sophisticated objective function in the optimization method or increasing the number of iterations. The effect of using these different methods on SIF and T-stress determination was explored. The Y/phase-image technique as well as the GA/DS technique were used with three terms of Williams's solution to determine the SIF and T-stress, and results are shown in Fig. 6. It can be observed that for the SIF determination (Figs 6(b) and (c)) the proposed $\mathrm{Y} /$ phase-image technique does give results that are closer to the FEA values than the GA/DS technique, but this difference is not significant for the majority of cases. However, it seems that the T-stress results (Fig. 6(a)) are much more sensitive than the SIF values to the crack tip position. The crack tips found using the GA/DS method introduce significant errors, both in sign (e.g. cases 1 and 2) and magnitude (e.g. case 3) of the determined T-stresses. The proposed Y/phase technique can be implemented in such a way that eliminates the need for an operator to locate the crack tip. In addition, this technique is fast and does not need a large amount of memory and central processing unit (CPU) resources. Consequently it has the potential to be used in a fully automated system to monitor fatigue crack paths during tests and to determine the corresponding parameters, SIF and T-stress, in almost real-time conditions.

Figure 7 shows the thermoelastic data from three DEC specimens each with an offset of $8 \mathrm{~mm}$ (the experimental details are given in Table 4 and the specimen dimensions in Fig. 3). The loads in Table 4 correspond to a nominal stress range of $25 \mathrm{MPa}$. The 


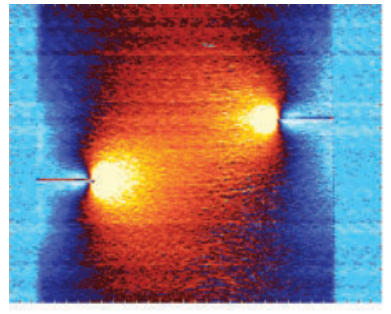

Cases 7, 10

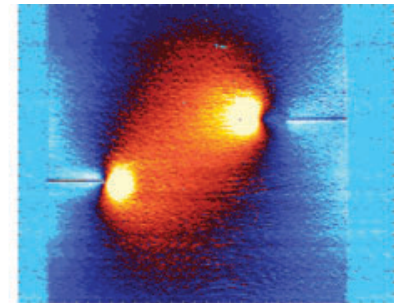

Cases 8,11

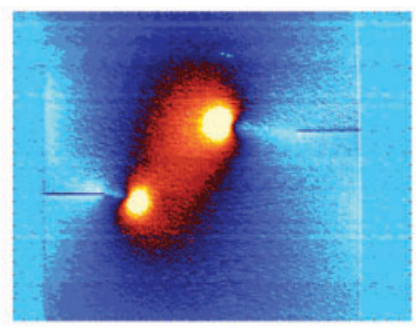

Cases 9, 12

Fig. 7 Thermoelastic images of interacting cracks from the DEC specimens with an $8 \mathrm{~mm}$ offset detailed in Table 4

crack tip was found using the $Y$ / phase image and the $\mathrm{T}$-stress was determined using three terms of Williams's equations. The results are shown in Fig. 8. In previous work [11] it was shown that such geometry is difficult to model accurately using numerical techniques and thus the thermoelastic method presented here allows valuable crack tip parameter information to be determined. According to Cotterell's theory [7], since all these T-stresses are negative then the cracks are directionally stable.

\section{CONCLUSIONS}

T-stress and SIFs have been determined from the thermoelastic data using up to three terms of Williams's formulation with a least squares techni-

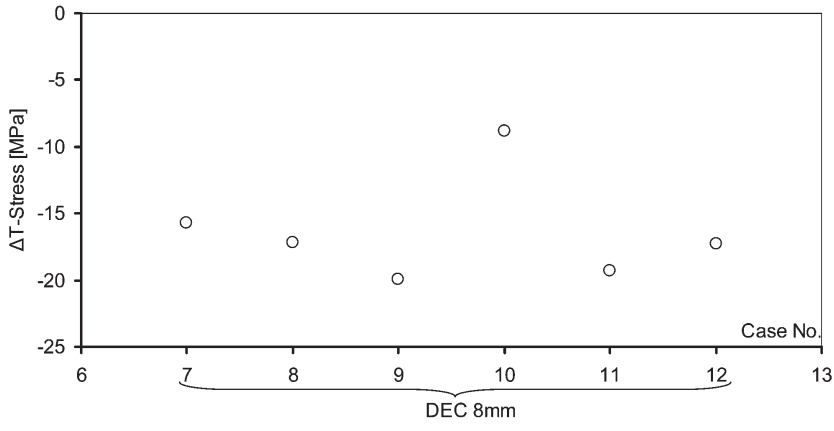

Fig. 8 Experimental $\Delta \mathrm{T}$-stresses for DEC specimens with an $8 \mathrm{~mm}$ offset. The images are shown in Fig. 7

que. The Muskhelishvili technique has also been used to determine the SIFs only. The results have been compared with FE simulations. It has been shown that Muskhelishvili and the two-term Williams's solutions both give the same results and using them to determine the SIFs does not affect the accuracy of the results significantly when compared with using three terms of Williams's solution. However, the two-term Williams's solution is not sufficient to determine the T-stress accurately and the results for T-stress using this model are dissimilar to those predicted by the FE method. It has been shown that using up to three terms of the Williams's solution makes it possible to determine both the SIF and T-stress accurately. It has been shown that the $\mathrm{T}$-stress results are sensitive to the crack tip position. A new technique was proposed to find the crack tip from thermoelastic images based on the Y or phaseimage. It has been shown that this technique is much more reliable than the other technique attempted, especially in T-stress determination, and it has a great potential to be used in fully automatic and real-time fatigue crack tip monitoring applications.

Table 4 Experimental details for the DEC specimens used in the T-stress determination

\begin{tabular}{|c|c|c|c|c|c|c|c|}
\hline \multirow[b]{2}{*}{ Case no. } & \multirow[b]{2}{*}{ Type } & \multirow[b]{2}{*}{ Material } & \multirow[b]{2}{*}{ Notch length (mm) } & \multirow{2}{*}{$\begin{array}{l}\text { Fatigue crack length } \\
(\mathrm{mm})\end{array}$} & \multirow[b]{2}{*}{ Frequency $(\mathrm{Hz})$} & \multicolumn{2}{|c|}{ Loading $(\mathrm{kN})$} \\
\hline & & & & & & $\overline{\Delta F_{x}}$ & $\Delta F_{y}$ \\
\hline 7 & $\begin{array}{l}\text { DEC } 8 \text { offset, right } \\
\text { crack }\end{array}$ & $\mathrm{Al} 7010$ & 8 & 0 & 20 & 0 & 1 to 7 \\
\hline 8 & $\begin{array}{l}\text { DEC } 8 \text { offset, right } \\
\text { crack }\end{array}$ & Al 7010 & 8 & 4 & 20 & 0 & 1 to 7 \\
\hline 9 & $\begin{array}{l}\text { DEC } 8 \text { offset, right } \\
\text { crack }\end{array}$ & Al 7010 & 8 & 8 & 20 & 0 & 1 to 7 \\
\hline 10 & $\begin{array}{l}\text { DEC } 8 \text { offset, left } \\
\text { crack }\end{array}$ & Al 7010 & 8 & 0 & 20 & 0 & 1 to 7 \\
\hline 11 & $\begin{array}{l}\text { DEC } 8 \text { offset, left } \\
\text { crack }\end{array}$ & Al 7010 & 8 & 1 & 20 & 0 & 1 to 7 \\
\hline 12 & $\begin{array}{l}\text { DEC } 8 \text { offset, left } \\
\text { crack }\end{array}$ & Al 7010 & 8 & 3.4 & 20 & 0 & 1 to 7 \\
\hline
\end{tabular}




\section{REFERENCES}

1 Larsson, S. G. and Carlsson, A. J. Influence of nonsingular stress terms and specimen geometry on small scale yielding at crack tips in elastic-plastic materials. J. Mech. Phys. Solids, 1973, 21, 263-277.

2 Williams, M. L. On the stress distribution at the base of a stationary crack. J. Appl. Mech., 1957, 24, 109-114.

3 Ayatollahi, M. R., Pavier, M. J., and Smith, D. J. Determination of $T$-stress from finite element analysis for mode I and mixed mode I/II loading. Int. J. Fracture, 1998, 91, 283-298.

4 Leevers, P. S. and Radon, J. C. Inherent stress biaxiality in various fracture specimen geometries. Int. J. Fracture, 1982, 19, 311-325.

5 Ayatollahi, M. R., Pavier, M. J., and Smith, D. J. Mode I cracks subjected to large T-stresses. Int. J. Fracture, 2002, 117, 159-174.

6 Erdogan, F. and Sih, G. C. On the crack extension in plates under plane loading and transverse shear. J. Basic Engng, 1963, 85, 519-527.

7 Cotterell, B. Notes on the paths and stability of cracks. Int. J. Fracture, 1966, 2(3), 526-533.

8 Roychowdhury, S. and Dodds Jr, R. H. Effect of Tstress on fatigue crack closure in 3-D small-scale yielding. Int. J. Solids Struct., 2004, 41, 2581-2606.

9 Smith, D. J., Ayatollahi, M. R., and Pavier, M. J. The role of $\mathrm{T}$-stress in brittle fracture for linear elastic materials under mixed-mode loading. Fatigue Fract. Engng Mater. Struct., 2001, 24(2), 137-150.

10 Sherry, A. H., France, C. C., and Goldthorpe, M. R. Compendium of $\mathrm{T}$-stress solutions for two and three dimensional cracked geometries. Fatigue Fract. Engng Mater. Struct., 1995, 18(1), 141-155.

11 Yates, J. R., Zanganeh, M., Tomlinson, R. A., Brown, M. W., and Diaz, F. A. Crack paths under mixed mode loading. Engng Fract. Mech., 2008, 75, 319-330.

12 Tomlinson, R. A. and Olden, E. J. Thermoelasticity for the analysis of crack tip stress fields - a review. Strain, 1999, 35(2), 49-55.

13 Diaz, F. A., Patterson, E. A., Tomlinson, R. A., and Yates, J. R. Measuring stress intensity factors during fatigue crack growth using thermoelasticity. Fatigue Frac. Engng Mater. Struct., 2004, 27(7), 571-583.

14 Dulieu-Barton, J. M., Fulton, M. C., and Stanley, P. The analysis of thermoelastic isopachic data from crack tip. Fatigue Fract. Engng Mater. Struct., 2000, 23, 301-313.

15 Tomlinson, R. A., Nurse, A. D., and Patterson, E. A. On determining stress intensity factors for mixed mode cracks from thermoelastic data. Fatigue Fract. Engng Mater. Struct., 1997, 20(2), 217-226.

16 Stanley, P. and Chan, W. K. The determination of stress intensity factors and crack-tip velocities from thermoelastic infra-red emissions. In Proceedings of the International Conference on Fatigue of Engineering Materials and Structures (IMechE), Sheffield, September 1986, pp. 105-114, Vol.1, paper c262/86.

17 Dulieu-Barton, J. M. and Worden, K. Identification of crack-tip parameters using thermoelastic isopachics and differential evolution. Key Engng Mater., 2003, 245-246, 77-86.

18 ABAQUS/CAE V 6.6. Available at http://www.simulia. com/products/abaqus_cae.html.

19 Fett, T. T-stresses in rectangular plates and circular disks. Engng Fract. Mech., 1998, 60(5-6), 631-652.

20 Cotterell, B. and Rice, J. R. Slightly curved or kinked cracks. Int. J. Fracture, 1980, 16(2), 155-169.

\section{APPENDIX}

\section{Notation}

$A, B$

F

O

$r$

$\Delta K_{\mathrm{I}}$

$\Delta K_{\mathrm{II}}$

$\Delta T$

$\Delta\left(\sigma_{11}+\sigma_{22}\right)$

$\theta$

$\sigma_{x x}, \sigma_{y y}, \tau_{x y}$

$\sigma_{11}, \sigma_{22}$ coefficient of the third term of Williams's formulation load applied to the specimen order symbol distance from the crack tip

variation in the mode I SIF between the current state and the initial reference state of the system

variation in the mode II SIF between the current state and the initial reference state of the system

variation in the $\mathrm{T}$-stress between the current state and the initial reference state of the system

variation in the first stress invariant between the current state and the initial reference state of the system angle from the crack tip the stresses at the point of interest with distance, $r$, and angle, $\theta$, from the crack tip

the principal stresses at the point of interest with distance, $r$, and angle, $\theta$, from the crack tip 